\title{
Cephalic tetanus studied with single fibre EMG
}

\author{
JOSE M FERNANDEZ, M FERRANDIZ, L LARREA, R RAMIO, M BOADA \\ From the Servicio de Neurofisiologia Clinica, Ciudad Santiaria del Valle Hebrón, Universidad Autonoma de \\ Barcelona, Barcelona, Spain
}

SUMMARY In a case of cephalic tetanus with left facial spasms and trismus, the repetitive stimulation of the left facial nerve at 3,10 and $20 \mathrm{~Hz}$ showed no facilitation or decrement. The amplitudes of the blink reflex were $50 \%$ lower on the affected side. The silent period of the masseter muscles was shortened. Concentric needle examination of the masseters and left facial muscles disclosed an almost continuous involuntary firing of motor unit potentials. Single fibre EMG of the left frontalis muscle showed increased jitter and blocking in a significant proportion of the recorded potentials. Both jitter and blocking improved on higher innervation rates. All electrophysiological findings were normal on the second examination when the patient was asymptomatic. The single fibre EMG findings point to a presynaptic defect in the neuromuscular transmission in human tetanus.

The clinical manifestations of tetanus in mammals are mainly characterised by spasms produced by the central action of the tetanus toxin which provokes abnormal motoneuron activity. ${ }^{1}$ However, experimental studies have demonstrated that, in addition to its central effects, tetanus toxin also blocks neuromuscular transmission in rat, ${ }^{23}$ mouse $^{45}$ and goldfish-fin ${ }^{67}$ muscle by impairing the acetyl choline release at nerve terminals. In humans, muscle biopsy has shown myopathic changes in the acute stage of the illness ${ }^{89}$ and neurogenic atrophy in cases of chronic ${ }^{10}$ and neonatal tetanus. ${ }^{11}$ Electrophysiological investigations have shown denervation potentials in some cases of cephalic ${ }^{1213}$ and chronic ${ }^{10}$ tetanus, and an axonal neuropathy in the severe generalised form of the disease. ${ }^{14}$ Only in a few cases ${ }^{15}{ }^{16}$ has neuromuscular transmission been specifically tested, showing pathologic facilitation on repetitive stimulation at high frequencies in one case. ${ }^{15}$ Single fibre EMG allows detection of minor disturbances of the neuromuscular transmission before any abnormality

Address for reprint requests: José M Fernandez, MD, Servicio de
Neurofisiologia Clinica, Ciudad Sanitaria del Valle Hebron, Paseo
Valle Hebrón s/n, Barcelona 35, Spain.

Received 7 February 1983. Accepted 1 April 1983

Presented in part at the Advanced EMG and SFEMG Course and Symposium, Newcastle upon Tyne, 8-13 July 1982. can be seen with repetitive nerve stimulation. ${ }^{17-19}$ However, no single fibre EMG studies have been published in human tetanus to our knowledge. We report a case of cephalic tetanus in which single fibre EMG findings provided further evidence of a presynaptic defect.

\section{Case report}

A 58-year-old farmer was in good health until one month before admission when he had a car accident and lacerated the left side of his forehead. He had never had tetanus prophylaxis and antitoxin was not given at the time of the accident. Two days later, he developed stiffness and spasm of the left facial and neck muscles, difficulty in opening his mouth, dysphagia, insomnia and headache. As the symptoms persisted, he was referred for evaluation. On examination he was an alert and oriented patient with normal vital signs. Spasms of all the left facial muscles and trismus were prominent. The jaw jerk was brisk. Upon repeated volitional contraction of the facial muscles, the left facial spasm increased. On maximal effort there was no clear facial asymmetry. The remaining neurological examination including tone and stretch reflexes was normal. EEG, serum calcium and magnesium levels and cerebrospinal fluid also were normal. The diagnosis of tetanus was established and he was given active and passive tetanus immunisation, a short course of penicillin and $20 \mathrm{mg}$ diazepam every six hours. Four weeks later the symptoms had subsided. 


\section{Neurophysiological investigations}

Extensive electrophysiological investigations were performed on two different occasions, on admission and three months later. These included: (1) conventional EMG with concentric needle electrodes of left facial muscles, masseter muscles and several limb muscles, (2) motor and sensory conduction velocities as well as late responses using standard techniques, (3) silent period of the masseter muscles and left soleus, eliciting a $\mathrm{T}$ and an $\mathrm{H}$ reflex respectively, recording in both cases with needle electrodes, (4) $M$ responses of the frontalis, orbicularis oculi and orbicularis oris muscles, bilaterally, recorded with surface electrodes after supramaximal stimulation of the facial nerve. The neuromuscular transmission was tested stimulating the facial nerve supramaximally at 3,10 and 20 $\mathrm{Hz}$, (5) blink reflexes recorded simultaneously from both orbicularis oculi muscles with surface electrodes, stimulating percutaneously the supraorbital nerve with square pulses of 0.5 ms every 6 seconds, ${ }^{20}$ (6) single fibre EMG was performed in the left frontalis muscle. The jitter was measured manually ( $R 10)^{2122}$ on permanent recording obtained on a Medelec MS 6 equipment.

\section{Results}

The following investigations were normal on the first examination: concentric needle EMG of the deltoid, biceps, first dorsal interosseus, vastus medialis and tibialis anterior muscles; motor conduction velocity of the medial ulnar and posterior tibial nerves as well as $M$ wave shape and amplitude and $F$ response latency and amplitude in the corresponding muscles; sensory conduction velocity of the radial, median and sural nerves and the amplitude of their sensory nerve potentials; $\mathrm{H}$ reflex and the silent period of the left soleus muscle.

The $M$ response (negative deflection) recorded from the fontalis, orbicularis oculi and orbicularis oris muscles had symmetric latencies $(2.7,2.4$ and $3.5 \mathrm{~ms})$ and amplitudes $(2 \cdot 8,3 \cdot 1$ and $4 \mathrm{mV})$ respectively, and remained so three months later. On repetitive stimulation at 3,10 and $20 \mathrm{~Hz}$ there was no decrement or increment of the M-wave of the orbicularis oris muscle. Furthermore, there was no postactivation potentiation or exhaustion.

Concentric needle examination of the masseters, frontalis, orbicularis oculi and orbicularis oris muscles showed an almost continuous activity consisting of involuntary firing of a discrete number of motor units. No fibrillation or positive sharp waves were seen in the brief periods of rest. There was a full interference pattern on maximal voluntary contraction in all five muscles with an increased proportion of low amplitude, short duration polyphasic motor units. On the second examination, concentric needle EMG was normal. The silent period of both masseter muscles was shortened to $15 \mathrm{~ms}$ after eliciting a $\mathrm{T}$ reflex. Three months later it was found to be normal at $60 \mathrm{~ms}$.

\section{Blink reflex}

When stimulating the left (affected) side, the ipsilateral reflex responses appeared after 10 and $33 \mathrm{~ms}$. The contralateral late response was recorded after $32 \mathrm{~ms}$. On stimulating the right side, the latencies were 10 and $32 \mathrm{~ms}$ respectively, and the contralateral $32 \mathrm{~ms}$. On repeated test the amplitudes of both responses were always lower by $50 \%$ on the left side as compared to the right. Even the contralateral response recorded on the left side was $45 \%$ lower than the right one. After three months the responses were symmetrical.

\section{Single fibre EMG results}

Single fibre EMG was first performed four weeks after the onset of symptoms. Twelve out of 21 recorded pairs (57\%) showed increased jitter above
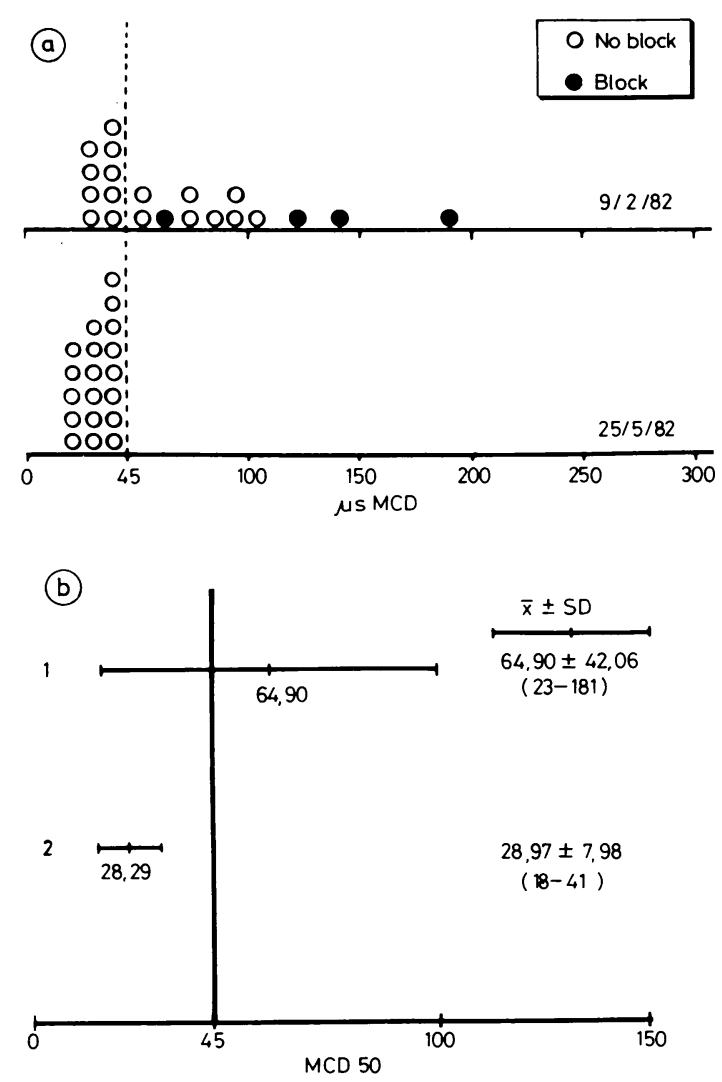

Fig 1 Left: abscissa shows the distribution of jitter values in $\mu s(M C D)$ at data indicated. Broken line at $45 \mu s$ shows the upper normal limit. Right: Mean value and standard deviation of jitter of all the potentials studied at each examination. 

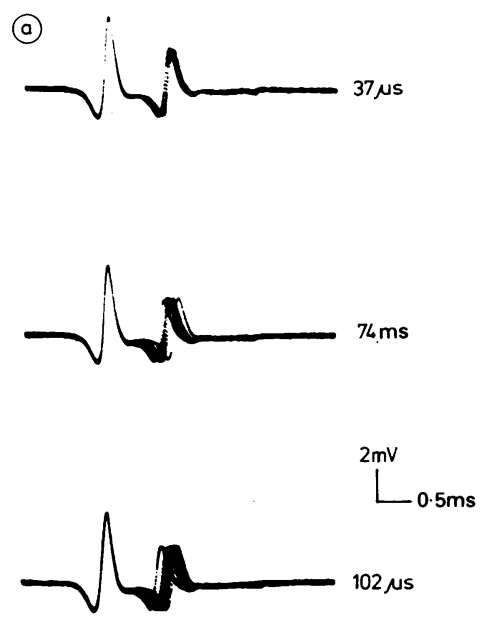

(b)
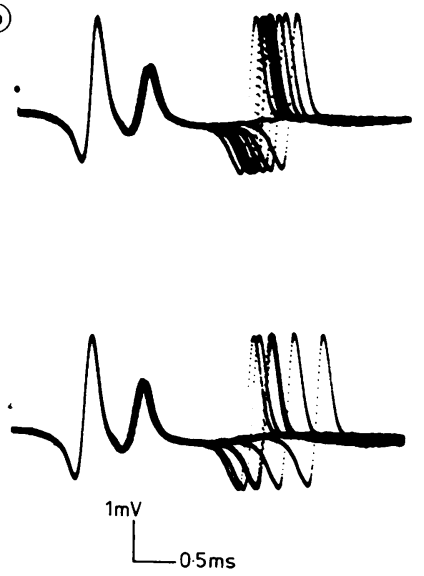

(c)
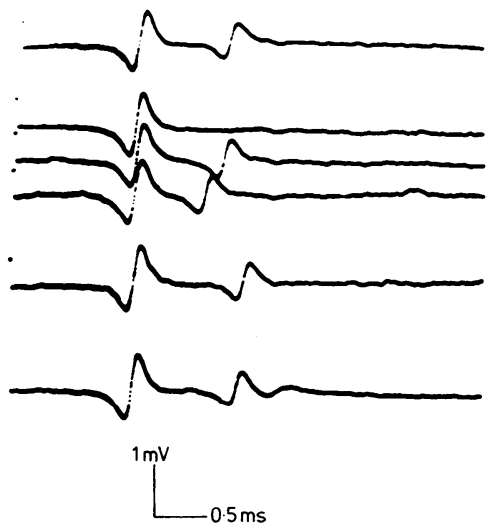

Fig 2 (a) A pair with increased jitter at rather low but regular firing rates (bottom). When the innervation rate increases slightly the jitter is reduced (middle recording). A further increase in the firing rate normalıs ss the jitter (top recording). (b) the second potential has a normal jitter (about $37 \mu \mathrm{s})$. The third has a very increased jitter and blocking (bottom) that improve after increasing the innervation rates (top). (c) sequence of 6 discharges at different IDIs (top to bottom). Short IDIs after the 2 nd and 3 rd discharges restore blocking and reduce the IPI.

$45 \mu \mathrm{s}$ and four of them (about $20 \%$ ) had intermittent blocking. The jitter values varied from 23 to $181 \mu$ s (mean $64.9 \pm 42 \mu \mathrm{s}$, fig 1 ). Only one pair with intermittent blocking showed jitter values below $120 \mu \mathrm{s}$. Occasionally, different spike components belonging to one and the same motor unit could have normal and abnormal jitter (fig 2a). In almost every abnormal pair the jitter was clearly dependent on the discharge rate, that is, higher innervation rates decreased the jitter values and the number of blockings and vice versa. This phenomenon was particularly well seen in pairs with good voluntary control (fig 2 b), although no quantitative correlation could be made. In some pairs with interval between the two components less than $4 \mathrm{~ms}$, the interpotential interval (IPI) showed dependence on the previous inter-discharge interval (IDI): the IPI decreased when the preceding IDI was shorter (fig 2c). On the second examination, three months later, all of 19 studied potential pairs had a normal jitter (mean 28.97 $\pm 7.98 \mu \mathrm{s}$ ), and the described phenomena were not seen any longer (fig 1).

\section{Discussion}

It is generally accepted that spontaneous firing of motor unit potentials, ${ }^{1323-28}$ an abnormally brisk jaw jerk, ${ }^{29}$ shortening or absence of the proprioceptive silent period in the masseter muscle, ${ }^{25} 2730$ and decreased amplitude of the blink reflex ${ }^{1526}$ are typical although inconstant findings in both cephalic and generalised tetanus. Several mechanisms have been invoked to explain these findings: damage to motoneurons, ${ }^{31}$ dysfunction or lesion of interneurons, ${ }^{29}{ }^{32}$ depression of inhibitory synapses ${ }^{12833}$ and gamma hyperactivity. ${ }^{34} 35$ However, none of these mechanisms can by itself provide a satisfactory explanation for all of the electrophysiological findings and probably all of them play a role in the pathogenesis of the central actions of tetanus toxin. ${ }^{29} 34$

Tetanus toxin binds specifically to two gangliosides, GT1 and GD1b, which are the receptors on neuronal cell membranes. ${ }^{36}$ The toxin is taken up by motor, sensory and autonomic nerve terminals ${ }^{37}$ and carried toward the spinal cord or brain stem by retrograde axonal transport, ${ }^{38}$ reaching the perikarya of motor neurons..$^{30}$ Subsequently, the toxin is trans-synaptically transferred to the presynaptic terminals in the neuropil of the ventral horn. ${ }^{4041}$ This explains the variable onset of symptoms: the shorter the axon, the earlier the involvement. A significant amount of toxin remains confined to nerve terminals at the neuromuscular junction $^{42}$ and produces a presynaptic block by interfering with acetyl choline release, resulting in a reduced frequency and probably amplitude of the MEPPs $^{45}$ and decreased amplitude of the EPPs. ${ }^{53}$ Experimentally, these effects are indistinguishable from those produced by botulinum toxin, except that the latter are more marked.45743-46 Furthermore, the ultrastructural changes found in the end 
plate and muscle after injection of tetanus toxin are similar to those seen in experimental botulinum intoxication..$^{47-51}$

On the first examination with single fibre EMG, one month after the onset of symptoms, the jitter was increased in $57 \%$ of the recorded pairs, with partial blocking in about $20 \%$. Impulse blocking occurred when jitter was higher than $120 \mu$ s except in one pair that showed intermittent blockings with a rather low jitter of $55 \mu \mathrm{s}$. This unusual phenomenon has been described in cases of myasthenic syndrome $^{52}$ and botulism ${ }^{18}$ and could be explained by a stepwise decrease of the EPPs amplitude. Increased jitter and blocking also occur in myasthenia gravis, ongoing denervation and reinnervation. ${ }^{22}$ The possibility that increased jitter and blocking were actually due to distal axonal involvement appears unlikely, as in this case (as in myasthenia gravis) increased discharge rates should result in increased rather than reduced jitter and blocking. In our patient, increment of firing rates typically resulted in a reduction of the jitter values and partially overcame the blocking. Such facilitation of neuromuscular transmission has been well documented in human botulism ${ }^{18}$ and myasthenic syndrome $\mathrm{e}^{5253}$ and points to the presynaptic nature of the disturbance. $^{5253}$ Also, the observed shortening of the IPIs following shorter IDIs, which is usually interpreted as a result of increased muscle fibre propagation velocity ${ }^{22}$ is in our case believed to be due to facilitated neuromuscular transmission and consequently shorter delay at the motor end plate. Reduction of the safety factor of neuromuscular transmission in disorders associated with presynaptic defects is due to a disturbance in the release of acetyl choline quanta from the nerve terminals. ${ }^{5455}$ The impaired release results in EEPs with marked amplitude variability, some being too small to trigger muscle fibre action potentials. A probable explanation for the deficient release of acetyl choline quanta is a disorder of calcium uptake at nerve terminals, which is necessary for the depolarisation-secretion coupling. Guanidine, 4-aminopyridine and repetitive stimulation increase the amount of transmitter released by nerve terminals, restoring the neuromuscular transmission. ${ }^{54565556}$ These substances have not been tested in our patient.

Repetitive stimulation at $20 \mathrm{~Hz}$ failed to induce facilitation. This may be explained by the relatively small proportion of pairs with partial blocking. A significant degree of facilitation is only seen when more than about $60 \%$ of the muscle fibres block. ${ }^{18}$

The single fibre EMG data obtained in our case are qualitatively identical to those found in cases of botulism and myasthenic syndrome and, therefore, strongly support the hypothesis of a presynaptic defect in neuromuscular transmission in human tetanus.

We are very grateful to Professor Jože Trontelj for his encouragement and helpful criticisms. We also thank Mr Miloš Kogej for preparing this manuscript. The work was supported by a grant of the Fondo de Investigaciones Sanitarias de la Seguridad Social.

\section{References}

${ }^{1}$ Brooks VB, Curtis DR, Eccles JC. The action of tetanus toxin on the inhibition of motoneurons. J Physiol (Lond) 1957;135:655-72.

${ }^{2}$ Kaeser HE, Saner A. The effect of tetanus toxin on neuromuscular transmission. Europ Neurol 1970;3: 193-205.

${ }^{3}$ Kryzhanovsky GN. The mechanism of action of tetanus toxin; effect on synaptic processes and some particular features of toxin binding by nervous tissue. Naunyn Schmiedebergs Arch Pharmacol 1973;276:247-70

${ }^{4}$ Duchen LW, Tonge DA. The effects of tetanus toxin on neuromuscular transmission and on the morphology of motor end-plates in slow and fast skeletal muscle of the mouse. J Physiol (Lond) 1973;228:157-72.

${ }^{5}$ Haberman E, Dreyer F, Bigalke H. Tetanus toxin blocks the neuromuscular transmission in vitro like Botulinum A toxin. Naunyn Schmiedebergs Arch Pharmacol 1980;311:33-40.

${ }^{6}$ Diamond J, Mellanby J. The effect of tetanus toxin in the goldfish. J Physiol (Lond) 1971;215:727-41.

${ }^{7}$ Mellanby J, Thompson PA. The effect of tetanus toxin at the neuromuscular junction in the goldfish. $J$ Physiol (Lond) 1972;224:407-19.

${ }^{8}$ Barua AR, Pal NC, Ghose BP. Tetanus myopathy. Indian J Med Res 1976;64:673-9.

${ }^{9}$ Eyrich K, Agostini B, Schulz A, Muller E, Noetzel H, Reichenmiller HE, Wiemars K. Klinische und morphologische Beobachtungen von Skelettmuskelveränderungen beim Tetanus. Dtsch Med Wochenschr. 1967;92:530-40.

${ }^{10}$ Risk WS, Bosch EP, Kimura J, Cancilla PA, Fischbeck KH, Layzer RB. Chronic tetanus: clinical report and histochemistry of muscle. Muscle Nerve 1981;4:3636.

" Gadoth N, Dagan R, Sandbank U, Levy D, Moses SW. Permanent tetraplegia as a consequence of tetanus neonatorum. J Neurol Sci 1981;51:273-8.

${ }^{12}$ Dastur FD, Shahani MT, Dastoor DH, et al. Cephalic tetanus: demonstration of a dual lesion. J Neurol Neurosurg Psychiatry 1977;40:782-6.

${ }^{13}$ Vakil BL, Singhal BS, Pandya SS, Irani PF. Cephalic tetanus. Neurology (Minneap) 1973;23:1091-6.

${ }^{14}$ Shahani MT, Dastur FD, Dastoor DH, et al. Neuropathy in tetanus. J Neurol Sci 1979;43:173-82.

15 Mamoli B, Ludin HP. Electrophysiological investigations in a case of cephalic tetanus. J Neurol 1977;214:251-5.

${ }^{16}$ Kaeser HE, Müller HR, Friedrich B. The nature of tetraplegia in infectious tetanus. Europ Neurol 
1968;1:17-27.

${ }^{17}$ Stålberg E, Trontelj J, Schwartz MS. Single muscle fibre recording of the jitter phenomenon in patients with myasthenia gravis and in members of their families. Ann NY Acad Sci 1976;274:189-262.

${ }^{18}$ Schiller HH, Stålberg E. Human botulism studied with single fibre electromyography. Arch Neurol 1978;35:346-9.

19 Stålberg E. Clinical electrophysiology in myasthenia gravis. J Neurol Neurosurg Psychiatry 1980;43:62233.

${ }^{20}$ Delwaide PJ. Electrophysiological exploration of the facial nerve. In: Cobb WA, Van Duijn H, eds. Contemporary Clinical Neurophysiology, Electroencephalogr Clin Neurophysiol (Suppl. No 34). Amsterdam: Elsevier Scientific Publ Co, 1978:393-403.

${ }^{21}$ Ekstedt J, Nilsson G, Stålberg E. Calculation of the electromyographic jitter. J Neurol Neurosurg Psychiatry 1974;37:526-39.

${ }^{22}$ Stålberg E, Trontelj JV. Single Fibre Electromyography. Woking (UK): Mirvalle Press, 1979.

${ }^{23}$ Farquharson RG. Cephalic tetanus. Proc $R$ Soc Med 1972;65:875-6.

${ }^{24}$ Garcia Mullin R, Daroff RB. Electrophysiological investigations of cephalic tetanus. J Neurol Neurosurg Psychiatry 1973;36:296-301.

${ }^{25}$ Kunze K. Neurophysiologische Befunde bei manifestem Tetanus. Langenbecks Arch Chir 1969;325:903-9.

${ }^{26}$ Ricker K, Eyrich K. Elektrophysiologische Untersuchung der Fazialislähmung bei Tetanus. J Neurol 1974;207:155-63.

${ }^{27}$ Struppler A, Struppler E, Adams RD. Local tetanus in man. Arch Neurol 1963;8:162-78.

${ }^{28}$ Wilson VJ, Diecke FPJ, Talbot WHJ. Action of tetanus toxin in conditioning of spinal motor neurons. $J$ Neurophysiol 1960;23:659-66.

${ }^{29}$ Bratzlavsky M, van der Eecken $\mathbf{H}$. Medullary actions of tetanus toxin. Arch Neurol 1976;33:783-5.

${ }^{30}$ Ricker K, Eyrich K, Zwikner R. Seltenere Formen von Tetanuserkrankung. Arch Psychiat Nervenkr 1971; 215:75-91.

${ }^{31}$ Tarlov IM. Rigidity and primary motoneuron damage in tetanus. Exp Neurol 1974;44:246-54.

${ }^{32}$ Foster JB, Matzke HA. Neurocytology of experimental ascending tetanus. World Neurol 1961;2:22-35.

${ }^{33}$ Curtis DR. Pharmacological investigations upon inhibition of spinal motoneurones. J Physiol (Lond) 1959;145:175-92.

${ }^{34}$ Bratzlavsky $\mathbf{M}$, van der Eecken $\mathbf{H}$. La physiopatholgie de l'hypertonie musculaire du tétanos. Rev Neurol (Paris) 1980;136:815-23.

${ }^{35}$ Takano K, Henatsch HD. Tension-extension diagram of the tetanus intoxicated muscle of the cat. Naunyn Schmiedebergs Arch Pharmacol 1973;276:421-36.

${ }^{36}$ Bizzini B. Tetanus toxin. Microbiol Rev 1979;43:224 40.

${ }^{37}$ Stöckel K, Schwab M, Thoenen H. Comparison between the retrograde transport of nerve growth factor and tetanus toxin in motor, sensory, and adrenergic neurons. Brain Res 1975;99:1-16.

${ }^{38}$ Price DL, Griffin JW. Tetanus toxin: Retrograde axonal transport of. systematically administered toxin. Neurosci Lett 1977;4:61-5.

${ }^{39}$ Dimpfel W, Haberman E. Histoautoradiographic local- ization of ${ }^{125} I$ labeled tetanus toxin in rat spinal cord. Naunyn Schmiedebergs Arch Exp Path Pharmak 1973;290:177-82.

${ }^{40}$ Schwab ME, Thoenen $H$. Electron microscopic evidence for a transsynaptic migration of tetanus toxin in spinal cord motor neurons: an electron microscopic and morphometric study. Brain Res 1976;105:213-27.

${ }^{41}$ Schwab M, Suda K, Thoenen N. Selective retrograde transsynaptic transfer of a protein, tetanus toxin, subsequent to retrograde axonal transport. $J$ Cell Biol 1979;82:798-810.

${ }^{42}$ Price DL, Griffin JW, Peck K. Tetanus toxin: evidence for binding at presynaptic nerve endings. Brain Res 1977;121:379-84.

${ }^{43}$ Wendon LMB. On the action of tetanus toxin at the rat neuromuscular junction. J Physiol (Lond) 1980; 300:23P.

${ }^{44}$ Kao I, Drachman DB, Price DL. Botulinum toxin: mechanism of presynaptic blockade. Science 1976;193:1256-8.

${ }^{45}$ Cull-Candy SG, Lundh H, Thesleff S. Effects of botulinum toxin on neuromuscular transmission in the rat. J Physiol (Lond) 1976;260:177-203.

${ }^{46}$ Lundh H, Leander S, Thesleff S. Antagonism of the paralysis produced by botulinum toxin in the rat: the effects of tetraethyl ammonium, guanidine and 4-amino pyridine. J Neurol Sci 1977;32:29-43.

${ }^{47}$ Duchen LW. Changes in motor innervation and cholinesterase localization induced by botulinum toxin in skeletal muscle of the mouse: differences between fast and slow muscles. $J$ Neurol Neurosurg Psychiatry 1970;33:40-54.

${ }^{48}$ Duchen LW. An electron microscopic study of the changes induced by botulinum toxin in the motor end-plates of slow and fast skeletal muscles fibres of the mouse. J Neurol Sci 1971;14:61-74.

${ }^{49}$ Duchen LW. The effects of tetanus toxin on the motor end-plates of the mouse-An electron microscopic study. J Neurol Sci 1973;19:153-67.

${ }^{\text {so }}$ Duchen LW. The local effects of tetanus toxin on the electron microscopic structure of skeletal muscle fibres of the mouse. J Neurol Sci 1973;19:169-77.

s1 Duchen LW, Strich SJ. The effects of botulinum toxin on the pattern of innervation of skeletal muscle in the mouse $Q J$ Exp Physiol 1968;53:84-9.

s2 Henriksson KG, Nilsson O, Rosen I, Schiller H. Clinical, neurophysiological and morphological findings in Eaton-Lambert syndrome. Acta Neurol Scand 1977;56:117-40.

${ }^{53}$ Schwartz MS, Stålberg E. Myasthenic syndrome studied with single fiber electromyography. Arch Neurol 1975;32:815-7.

${ }^{54}$ Lambert EH, Elmqvist D. Quantal components of endplate potentials in the myasthenic syndrome. Ann NY Acad Sci 1971;183:183-99.

ss Lambert EH, Engel AG, Cherington M. End-plate potentials in human botulism. In: Third International Congress on Muscle Diseases. Amsterdam: Excerpta Medica 1974;334:65.

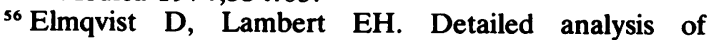
neuromuscular transmission in a patient with the myasthenic syndrome sometimes associated with bronchogenic carcinoma. Mayo Clin Proc 1968;43: 689-713. 